\title{
Factors influencing transitional care from adolescents to young adults with cancer in Taiwan: A population-based study
}

\author{
Yo-Ting Jin ${ }^{1}$, Chin-Mi Chen ${ }^{1,2^{*}}$ and Wu-Chien Chien ${ }^{3,4}$
}

\begin{abstract}
Background: To investigate the progress of transition from paediatric to adult health care for patients with cancer in Taiwan's medical system.

Methods: The data were retrieved from the Longitudinal Health Insurance Database (LHID), which contains the original inpatient and outpatient medical claims data for 1,000,000 enrollees randomly sampled from the NHIRD between 1997 and 2010.

Results: Among the 1,411 cancer patients selected for this study, $98.09 \%$ received adult-oriented therapy before the age of 18. In addition, only $1.91 \%$ of the patients received paediatric-oriented therapy during adolescence. The primary factors that determine whether these patients would receive paediatric-oriented therapy or adult-oriented therapy at an early age were as follows: the age of the patient at the first visit and the performance-level of the hospital $(p<0.001)$.

Conclusions: Previous studies conducted in developed countries have demonstrated that the unwillingness of patients to switch from paediatric-oriented therapy to adult-oriented therapy being the major obstacle that hinders the transition process. However, this study revealed a different result: the implementation of the National Health Insurance system in Taiwan makes healthcare affordable for the adolescent patients who may not possess adequate knowledge about paediatric health care and may not appreciate paediatric-oriented therapy, thereby hindering the transition process.
\end{abstract}

Keywords: Transitional care, Adolescent, Cancer, Children with special health care needs

\section{Background}

In recent years, with the significant advances in medical science and technology, more children with chronic diseases can survive into adulthood [1-3]. Childhood cancer in particular exhibits a high survival rate of approximately $80 \%$ [4]. Consequently, when transitioning from paediatric to adult healthcare services, these children, their families, and healthcare providers may encounter numerous potential problems, such as adult health insurance, adaptation to adult life, and financial conditions that create specific healthcare needs [5-9], because the

\footnotetext{
* Correspondence: fdi613@yahoo.com.tw

${ }^{1}$ The Graduate Institute of Medical Sciences, National Defense Medical Center, Taipei, Taiwan

2Department of Nursing, Fu Jen Catholic University, Taipei, Taiwan

Full list of author information is available at the end of the article
}

healthcare environment for children must be changed from dependent to independent [10-12].

Transitional care is widely defined as "the purposeful, planned movement of adolescents and young adults with chronic physical and medical conditions from childcentered to adult-oriented healthcare systems" [13]. An effective transition process can provide appropriate, high-quality, and uninterrupted medical care services for the patient, as well as a communication platform for the main participants in the patient's treatment, including the patient, family members, paediatricians, nurses, adulthealthcare providers, and other healthcare professionals [14-22], to enhance the patient's health, life outcomes, self-management and autonomy [23, 24].

In developed western countries such as the United Kingdom and Australia, the transitional medicine is 
supported by the government and has been implemented for years [25]. In United States, some individual states and health services have recognised the importance of transition and the need for formal approaches to transition planning [26]. Numerous researchers have demonstrated that the bond formed among the patients, their families, and adult-healthcare providers during transitional care provides excellent results, including reduced length of stay [27], reduced medical costs [28], and increased medical usage satisfaction of adolescent patients with chronic illnesses and their families [29, 30].

All previous research about the transition from paediatric care to adult health care has suggested that timing is critical for a successful transition. A transition process for all youth has been provided [31], as shown in Fig. 1. Age is one of the most frequently discussed predictors of the transition time decision [32]. Although no agreement has been reached on the appropriate age of transitional care in previous studies, numerous studies have indicated that an appropriately timed transition from a paediatric-oriented to an adult-oriented clinic typically should occur between 18 and 19 years of age [33-35]. Moreover, several obstacles to successful transitional care programs have been identified in the past decade, and these can be mainly divided as follows: unwillingness to leave familiar medical professionals and environments [32], unable to adapt to adult-oriented medical care [32], poor timing of transition [26], lack of adult medical services [36], lack of proper health insurance [4, 32], and absence of transitional care knowledge [37]. Particularly in continue having proper health insurance, another age-related concern, patients are discouraged to engage in their follow-up mainly due to lack of insurance as they grow up and become too old to participate in parental/public insurance and lack of fulltime employment $[38,39]$. Also, insurance policies often have restricted listings of contracted physicians, and finding someone with the willingness and expertise to follow up with childhood cancer survivors may be difficult [40].
Cultural and medical policies can also influence the implementation results or create new obstacles to transitional care. As shown in Fig. 2, for example, compared with the insurance and health care system in the United States, Taiwan's National Health Insurance allows unrestricted access to physicians of all specialties irrespective of age and personal finance. Therefore, lack of proper health insurance is not an obstacle transitioning from paediatric to other adult-oriented services. However, transition care services have not been completely established in Taiwan. It is difficult for patients to seek an appropriate specialist or medical service without the help of their primary care physicians if the patients lack medical knowledge. Moreover, only two studies related to transitional care in Asia have been conducted. Wong et al. [41] and Ishizaki et al. [42, 43] have investigated transitional care in Hong Kong and Japan, respectively, and the results indicated that both countries lack an established transition program from paediatric to adult healthcare services.

The goals of this study are to identify the characteristics of childhood cancer patients, and to investigate the progress of transition from paediatric to adult health care for these patients in Taiwan's medical system. The Taiwanese government initiated a single-payer National Health Insurance programme approximately 20 years ago; Taiwan's National Health Insurance system covers most forms of treatment, including general diagnoses and treatment, medical consultations and operations, and other related procedures such as examinations, laboratory tests, anaesthesia, prescription medications, supplies, nursing care, hospital admissions, and certain over-thecounter drugs. A family of four pays a premium of roughly United States Dollar (USD) $\$ 100$ per month, accounting for about $2 \%$ of the average household income. In addition, over 23 million people were enrolled in the National Health Insurance Research Database (NHIRD) after implementing the programme, thus granting researchers access to a large amount of samples for analysis. Compared with most previous studies

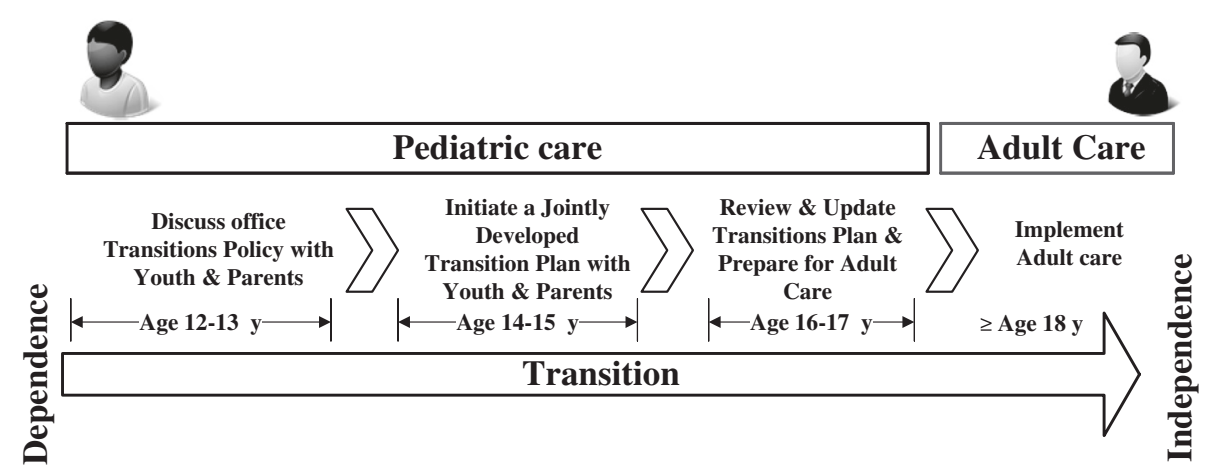

Fig. 1 A Transition Process from Paediatric to Adult Services 


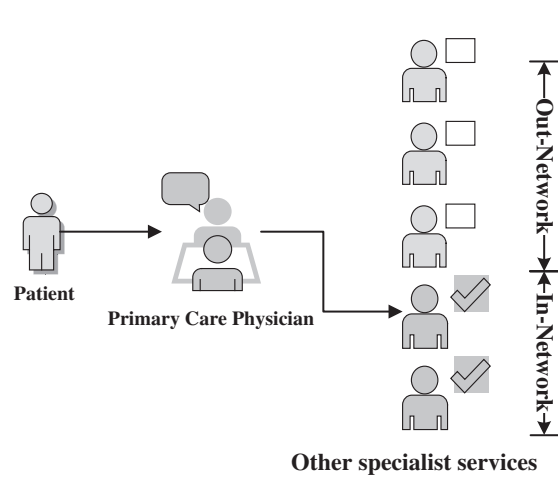

(A) The United States with Private Insurance System

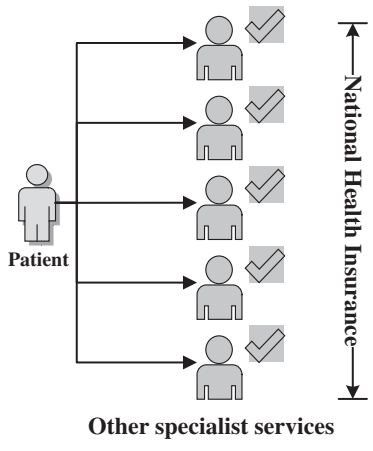

(B) Taiwan with National Health Insurance System

Fig. 2 The comparison of Health Insurance and Health care system between Taiwan and U.S.

on transitional care, which used questionnaire methods to determine the needs of a small number of patients, families, medical professionals, and adult-healthcare providers by interviewing them [32], the analytic results derived from a larger sample from the NHIRD are more reliable and more representative.

\section{Methods}

\section{Data source and sample}

In this study, the data were retrieved from the Longitudinal Health Insurance Database (LHID) 2005, which contains the original inpatient and outpatient medical claims data for 1,000,000 enrollees randomly sampled from the NHIRD between 1997 and 2010. We selected patients diagnosed with neoplasms before the age of 18 years based on the International Classification of Diseases, Ninth Revision (ICD-9) codes 140-239 and maintained an adult electronic medical record in the LHID 2005.

\section{Variables related to healthcare transition}

Dependent variables The Childhood Cancer Survivor Study revealed a phenomenon that approximately a third of young adult survivors experiencing difficulty in obtaining health insurance beginning at 18 years of age [39]. In comparison, the siblings of these young adults or those around the same age who are in good health do not share the same experience. In addition, 18 is the legal age of adulthood in Taiwan. Therefore, this study used the following criterion to identify patients who meets a well-timed transition: if a patient received paediatric services before the age of 18 years and adult-healthcare services in adulthood, a successful transfer was achieved; otherwise, no transitional care was received.

Independent variables In previous studies, patient characteristics and characteristics of medical service providers were common explanatory variables used to identify factors and barriers associated with transition decision. In this study, we used the performance-level of hospitals where patients visited prior to adulthood, and hospital location, the criteria obtained from the registration files of the LHID 2005, as the characteristics of medical service providers. The hospital performancelevels were assigned by a professional Taiwanese medical evaluation institution by performing objective assessments of the quality of medical services provided. Hospitals were categorized into one of the following three categories: academic medical centers (AMCs); superior in hospital accreditation and excellence in teaching hospital (SHET); and others. AMCs and SHET represent hospitals with the highest level of medical service quality according to the old and new evaluation systems, respectively. AMCs takes a more holistic approach in providing care to patients, including medical education and research, development of medical and health technology. In contrast, SHETs are based on patients' point of view and strive to provide all the relevant information to the patients' condition prior to giving any medical treatment. In other word, AMCs generally focus on teaching life-saving skills, whereas SHETs not only focus on teaching lifesaving skills, but also on teaching the purpose and the quality of the care provided. Hospital locations were divided into six major cities of Taiwan and nonmetropolitan regions based on the area classification of Taiwan. These major cities included Taipei, New Taipei, Taoyuan, Taichung, Tainan, and Kaohsiung. Urban regions were defined as areas with a population density of at least 1,500 people per square kilometer, and rural regions were defined as those with 1,499 or fewer people per square kilometer. The following information for patient characteristics was retrieved from the database: gender, average healthcare expenses and yearly clinical visit frequency before 18 years of age, cancer, and the age of first visit. Cancer was divided into single and multiple primary 
cancer types. Single primary cancer denotes patients with only one type of cancer, whereas multiple primary cancer represents patients with other complications as a result of the cancer(s) and other patients not classified in the single primary cancer category. Average medical expenses and clinical visit frequency both were divided into low and high level based on the average.

\section{Statistical analyses}

Frequency analysis, comprising $t$ tests for continuous data and multivariate logistic regression models for determining the independent contributions of explanatory variable to the appropriateness of transition time, was conducted in this study. A significance level of $\alpha=0.01$ was established to determine the significance of the results. Microsoft Access 2010 was used to filter all data and IBM SPSS 20.0 was employed to perform all statistical analyses.

\section{Results}

A total of 1,411 patients were selected for this study, and the characteristics of the sampled patients are summarized in Table 1. The subjects were aged 18-29-years, with a mean age of 20.97 years. 946 were female and 465 were male. There were $34.66 \%$ who had simple primary cancer. The majority of the patients received their first therapy in LHID between 15 and 18 years of age (75.97 \%), followed by $12-15$ years of age (18.50\%); only $0.85 \%$ of the patients age below 9 years of age. Hospital location distribution was $17.51 \%$ Taipei, $5.67 \%$ New Taipei, 9.64 \% Taoyuan, 6.87 \% Taichung, $4.11 \%$ Tainan, $10.84 \%$ Kaohsiung, and $45.36 \%$ Others. Hospital performance-level was $3.97 \%$ AMCs, $22.18 \%$ SHET and $73.85 \%$ others. A total of $78.10 \%$ of patients received care at clinics $0-2$ times per year on average before the age of 18 years. With respect to medical expenses, $53.08 \%$ of patients incurred an average expenditure of USD $\$ 3$ or less per visit before 18 years of age. The mean medical expense for receiving care at pediatric clinics was USD \$2.7 per visit, while the mean medical expense for receiving care at non-pediatric clinics was USD \$3.65 per year. The percentage of patients who incurred an annual expenditure of US $\$ 3.65$ or less per visit on adult-oriented medical expenses was $55.36 \%$; $3.05 \%$ of these patients incurred an expenditure of US \$2.7 or less per visit on paediatric-oriented medical expenses; and $94.61 \%$ of these patients had never receive paediatric-oriented therapy. For many patients, the first time they received adult-oriented therapy was between the ages of 15 and 18 years old (75.69\%). Another $22.40 \%$ of patients received adult-oriented therapy before the age of 15. The age for which patients received adult-oriented therapy $($ mean $=16.03, \mathrm{SD}=1.99)$ was significantly less than $18(p<0.001)$. Moreover, the frequency of yearly clinic visits for patients receiving transition cares was (Mean $=1.81, \mathrm{SD}=1.45, n=15)$ significantly lower than that of patients not receiving transition cares (Mean $=$ 3.73, $\mathrm{SD}=15.79, n=1,396 ; p=0.001)$.

Table 2 shows the factors associated with patient visits to adult-oriented care before the age of 18 years. In multivariate logistic regression, SHET (OR 9.044 [2.840, 28.807], $\beta=2.202, p<0.001)$ were positively associated with patient visits to adult-oriented care before the age of 18 years. Figure 3a shows that the rate of prematurely receiving adult-oriented care in hospitals accredited with SHET accounted for $93.29 \%$, lower than that of hospitals of AMCs and other performance-levels (100 and 99.42\%, respectively). The age of first visit (OR 0.738 [0.647, 0.842], $\beta=-0.304, p<0.001)$ was inversely associated with patient prematurely receive adult-oriented care. As shown in Fig. 3b, the rate of prematurely receiving adult-oriented care was $75 \%$ in $\leq 9$ years of age, $90.91 \%$ in 9-12 years of age, $96.17 \%$ in $12-15$ years of age, and $99.25 \%$ in 15-18 years of age. Other factors, including gender, cancer, hospital location, mean medical expenses per visit, and mean clinic visit frequency were not associated with patient visits to paediatric healthcare clinics before the age of 18 years.

\section{Discussion}

Previous studies have demonstrated that when insurance systems does not cover the medical expenses for adult health care, adolescent patients will prolong the period of paediatric health care [32]. In Taiwan, people can receive medical treatment at a low cost regardless of the type of care and the limitation of age because of National health insurance system. The mean medical expenses per visit is less than USD \$3. The financial burden borne by patients with cancer is less severe, and patients are able to switch from paediatric to adult health care without contemplating future medical expenses. Instances of delayed transition to adult care are relatively rare. Thus, the mean medical expense was not a significant barrier in the regression.

However, the vast majority of the patients begin receiving adult health care well before the age of 18 and few adolescent patients with cancer are provided a complete transition mechanism. In fact, the expenses of adultoriented health care are higher than those of pediatric health care $(p=0.01)$. But, patients' families are likely to favor adult-oriented therapy when choosing the medical facilities for their adolescent children. This would jeopardize the mental and physical development of children with cancer. Moreover, transition planning requires long-term preparation. Premature transition to adult-oriented therapy may lead to insufficient preparation, resulting in transition failure ${ }^{7}$. 
Table 1 Sample Characteristics of Participants $(N=1,411)$

\begin{tabular}{|c|c|c|c|c|}
\hline Character & Observation $(n)$ & Ratio (\%) & Mean & Standard Deviation (SD) \\
\hline Age (range $18-29$ years) & & & 20.97 & 2.30 \\
\hline \multicolumn{5}{|l|}{ Gender } \\
\hline Female & 946 & $67.04 \%$ & & \\
\hline \multicolumn{5}{|l|}{ Cancer } \\
\hline Simple primary & 489 & $34.66 \%$ & & \\
\hline Multiple primary & 922 & $65.34 \%$ & & \\
\hline \multicolumn{5}{|l|}{ Hospital } \\
\hline AMCs & 56 & $3.97 \%$ & & \\
\hline SHETS & 313 & $22.18 \%$ & & \\
\hline Others & 1042 & $73.85 \%$ & & \\
\hline \multicolumn{5}{|l|}{ Area } \\
\hline Taipei & 247 & $17.51 \%$ & & \\
\hline New Taipei & 80 & $5.67 \%$ & & \\
\hline Taoyuan & 136 & $9.64 \%$ & & \\
\hline Taichung & 97 & $6.87 \%$ & & \\
\hline Tainan & 58 & $4.11 \%$ & & \\
\hline Kaohsiung & 153 & $10.84 \%$ & & \\
\hline Others & 640 & $45.36 \%$ & & \\
\hline Age at first visit & & & 15.91 & 2.00 \\
\hline$<9$ & 12 & $0.85 \%$ & & \\
\hline $9-12$ & 66 & $4.68 \%$ & & \\
\hline $12-15$ & 261 & $18.50 \%$ & & \\
\hline $15-18$ & 1072 & $75.97 \%$ & & \\
\hline \multicolumn{3}{|c|}{ Clinic visit frequency (mean yearly) before age of 18} & 2.02 & 3.76 \\
\hline Low ( $\leq 2$ times) & 1102 & $78.10 \%$ & & \\
\hline High (> 2 times) & 309 & $21.90 \%$ & & \\
\hline \multicolumn{3}{|c|}{ Mean medical expenses per visit before age of 18} & 3.00 & 2.03 \\
\hline Low ( $\leq$ USD \$ 3 ) & 749 & $53.08 \%$ & & \\
\hline High (> USD \$3) & 662 & $46.92 \%$ & & \\
\hline \multicolumn{3}{|c|}{ The medical expenses of adult service (\$/time) } & 3.65 & 2.23 \\
\hline Low ( $\leq$ USD \$ 3.65) & 770 & $55.36 \%$ & & \\
\hline High (> USD \$ 3.65) & 629 & $45.22 \%$ & & \\
\hline No receiving adult service & 12 & $0.86 \%$ & & \\
\hline \multicolumn{3}{|c|}{ The medical expenses of pediatric service ( $\$ /$ time) } & 2.70 & 3.12 \\
\hline Low ( $\leq$ USD \$ 2.7) & 43 & $3.05 \%$ & & \\
\hline High (> USD \$ 2.7) & 33 & $2.34 \%$ & & \\
\hline No receiving pediatric care & 1335 & $94.61 \%$ & & \\
\hline \multicolumn{5}{|c|}{ Age at first receiving adult service } \\
\hline$<12$ & 67 & $4.75 \%$ & 16.03 & 1.99 \\
\hline $12-15$ & 249 & $17.65 \%$ & & \\
\hline $15-18$ & 1068 & $75.69 \%$ & & \\
\hline $18-21$ & 11 & $0.78 \%$ & & \\
\hline$\geq 21$ & 4 & $0.28 \%$ & & \\
\hline No receiving adult service & 12 & $0.85 \%$ & & \\
\hline
\end{tabular}


Table 2 Factors Associated with Receiving Care at Adult Health Care Clinics Before the Age of 18 Years on Multiple Logistic Regression Analysis

\begin{tabular}{|c|c|c|c|c|}
\hline \multirow[t]{2}{*}{ Variables } & \multicolumn{4}{|c|}{ Multivariate logistic regression } \\
\hline & $\beta$ & Odds Ratio (OR) & $95 \% \mathrm{Cl}$ & $p$ value \\
\hline \multicolumn{5}{|l|}{ Gender } \\
\hline Female & -0.844 & 0.430 & $0.184-1.005$ & 0.051 \\
\hline Male & \multicolumn{4}{|c|}{ Reference } \\
\hline \multicolumn{5}{|l|}{ Cancer } \\
\hline Simple primary & 0.173 & 1.189 & $0.486-2.905$ & 0.705 \\
\hline Multiple primary & \multicolumn{4}{|c|}{ Reference } \\
\hline \multicolumn{5}{|c|}{ Mean medical expenses per visit before age of 18} \\
\hline Low $(\leq$ USD \$3) & 0.912 & 2.489 & $1.020-6.077$ & 0.045 \\
\hline High (> USD \$3) & \multicolumn{4}{|c|}{ Reference } \\
\hline \multicolumn{5}{|c|}{ Clinic visit frequency (mean yearly) before age of 18} \\
\hline Low ( $\leq 2$ times) & 0.130 & 1.139 & $0.394-3.295$ & 0.810 \\
\hline High (>2 times) & \multicolumn{4}{|c|}{ Reference } \\
\hline The age of first visit & -0.304 & 0.738 & $0.647-0.842$ & $<0.001$ \\
\hline \multicolumn{5}{|l|}{ Hospital location } \\
\hline Taipei & -0.937 & 0.392 & $0.071-2.171$ & 0.284 \\
\hline New Taipei & 0.165 & 1.179 & $0.260-5.352$ & 0.831 \\
\hline Taoyuan & -16.151 & 0.000 & $0.000-$ & 0.997 \\
\hline Taichung & -0.242 & 0.785 & $0.137-4.501$ & 0.786 \\
\hline Tainan & 0.967 & 2.630 & $0.506-13.665$ & 0.250 \\
\hline Kaohsiung & -15.769 & 0.000 & $0.000-$ & 0.997 \\
\hline Non-metropolitan & \multicolumn{4}{|c|}{ Reference } \\
\hline \multicolumn{5}{|c|}{ Hospital Performance-level } \\
\hline AMCs & -15.405 & 0.000 & $0.000-$ & 0.997 \\
\hline SHETS & 2.202 & 9.044 & $2.840-28.807$ & $<0.001$ \\
\hline Others & \multicolumn{4}{|c|}{ Reference } \\
\hline
\end{tabular}

Taiwan Pediatrics Association has completed a survey of 14,730 parents in Taiwan via a web questionnaire. The results show that $83 \%$ of parents don't know their children should receive pediatric-oriented therapy before age of 18 and $58.5 \%$ of parents don't know which department their children should visit. In other words, the fact that patients and their families lack the knowledge related to pediatric health care could be the reason why patients did not receive any pediatric-oriented therapy or accepted adult-oriented therapy early. In Taiwan, most hospitals have a paediatric specialist that can treat those patients and hold a consultation with other specialists if necessary. But, hospitals accredited with the SHET have more complete healthcare systems and provide more comprehensive health education than do hospitals of other performance-levels. Patients receiving health care in these hospitals are more favourably positioned to learn about paediatric health care. The ratio of patients

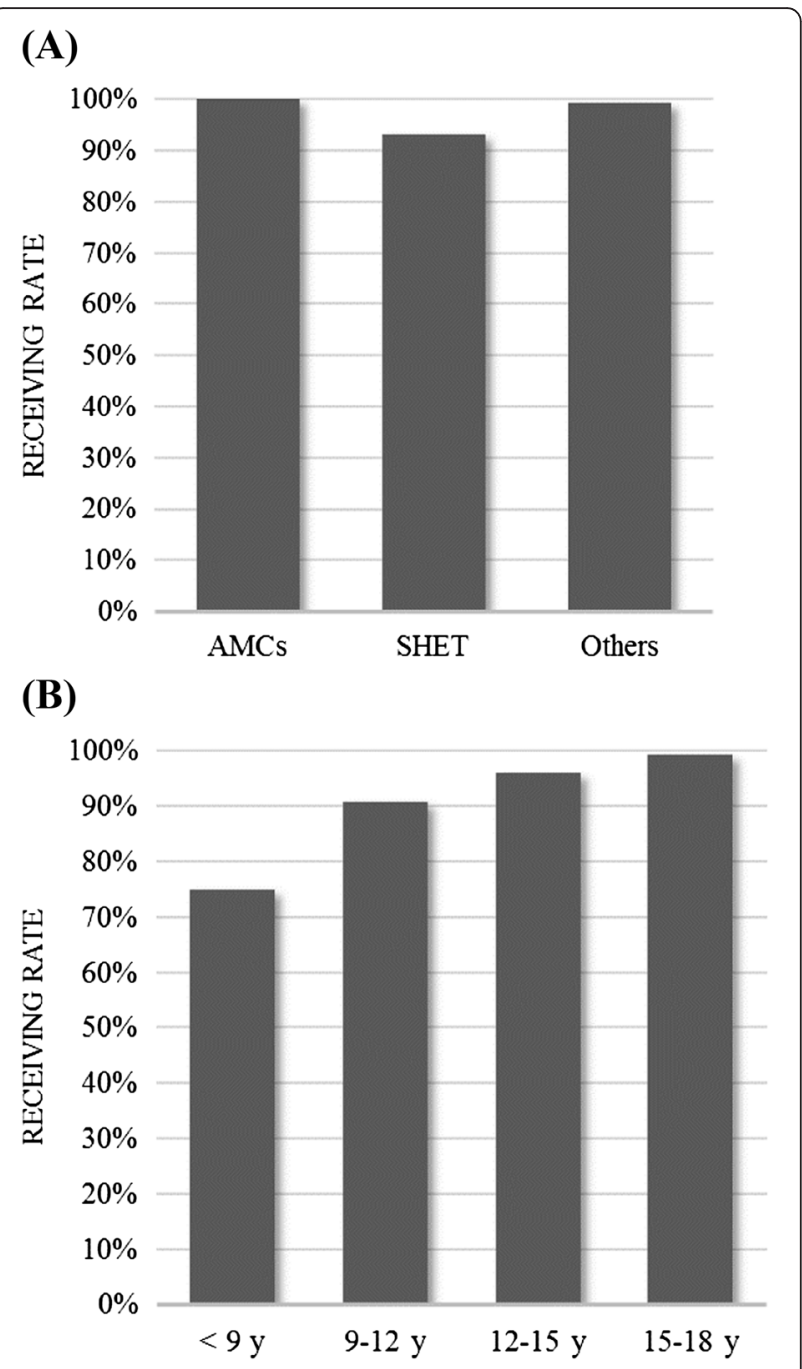

Fig. 3 Significant Factors Related to The Percentage of Patients Receiving Care in Pediatric Health Care Clinics Before the Age of 18 Years. a Hospital performance-level. b The age of first visit

prematurely receiving adult health care at hospitals accredited with the SHET was significantly lower than that of patients receiving care at hospitals of other performance-levels, which again well demonstrated that transition failure is due to patients' lack of understanding of the influence of paediatric health care on adolescent patients, the lack of a transition mechanism in hospitals, and hospitals failing to provide related information to patients and their families. Therefore, patients and their family members choose their health care based solely on the department's specialty (e.g., patients with cancer choosing the department of oncology), resulting in transition failure. In Taiwan, adolescent survivors and their family should be informed about the paediatric healthcare and the supporting groups that can assist in transitioning care.

In this study, the physicians'/pediatricians' views on transition care were not explored because the LHID 
contains only the circumstantial factors, such as medical expenses, hospital location and hospital performancelevel. However, the scope of the investigation has provided a relevant depiction of the effect of a low-cost health insurance system have on transitional care. A starting point has been provided by this study for factors to transitional care in areas that have implemented national health insurance.

\section{Conclusion}

As the survival rate of adolescent patients with cancer continues to rise, transition mechanisms also become increasingly vital. Transition mechanisms provide patients with appropriate health care as their demands change when transitioning from adolescence to adulthood. These mechanisms enhance their quality of life and reduce medical expenses. While researchers in numerous developed western countries have looked into various topics surrounding transitional care in recent years, in Asia, only researchers in Japan and Hong Kong have conducted similar research. These studies indicated that health insurance and unwillingness to leave familiar medical professionals and environments were the two common factors contributing to transition failure.

However, factors influencing the transition care differ between cultures and health policies. In this study, we conducted investigations to explore the situation of transition care for Taiwan, where the National Health Insurance system has been implemented. The major transition obstacles hindering the transition from paediatric to adult health care in Taiwan differ substantially from those suggested by previous studies. In Taiwan, the adolescents with cancer have a very short period of paediatric treatment or have never receive paediatric treatment. Lack of appropriate paediatric treatment is the very obstacle for successful transitional care.

\section{Abbreviations}

AMCs, Academic Medical Centers; LHID, longitudinal national health insurance research database; NHIRD, National Health Insurance Research Database; OR, odds ratio; SD, standard deviation; SHET, Superior in Hospital accreditation and Excellence in Teaching hospital; USD, United States Dollar.

\section{Acknowledgments}

This study is based in part on data from the National Health Insurance Research Database provided by the National Health Insurance Administration, the Ministry of Health and Welfare and maintained by the National Health Research Institute. The interpretations and conclusions contained herein do not necessarily represent those of the National Health Insurance Administration or the National Health Research Institute.

\section{Funding}

No funding to declare.

\section{Availability of data and material}

All relevant raw data are obtained from the NHIRD and cannot be shared freely without permission of the National Health Research Institutes in Taiwan.

\section{Authors' contributions}

YTJ conceived the study. YTJ and WCC completed all statistical analyses. YTJ and CMC drafted the manuscript. YTJ, CMC and WCC contributed to the discussion. YTJ revised the manuscript. All authors have read and approved the final manuscript.

\section{Competing interests}

The authors declare that they have no competing interests.

\section{Consent for publication}

Not applicable.

\section{Ethics approval and consent to participate}

This research is a secondary data analysis. The data have been reviewed and approved by NHIRD's Professional Peer Reviewer Committee. The patients' personal data have been encrypted and their privacy is protected in this research, thereby conforming to the Declaration of Helsinki.

\section{Author details}

${ }^{1}$ The Graduate Institute of Medical Sciences, National Defense Medical Center, Taipei, Taiwan. ${ }^{2}$ Department of Nursing, Fu Jen Catholic University, Taipei, Taiwan. ${ }^{3}$ Department of Medical Research, National Defense Medical Center, Tri-Service General Hospital, Taipei, Taiwan. ${ }^{4}$ School of Public Health, National Defense Medical Center, Taipei, Taiwan.

Received: 21 October 2015 Accepted: 26 July 2016

Published online: 02 August 2016

\section{References}

1. Por J, Golberg B, Lennox V, Burr P, Barrow J, Dennard L. Transition of care: health care professionals' view. J Nurs Manag. 2004;12:354-61.

2. Kennedy A, Sloman F, Douglass JA, Sawyer SM. Young people with chronic illness: the approach to transition. Intern Med J. 2007:37:555-60.

3. Riley K, Roth S, Sellwood M, Wyatt JS. Survival and neurodevelopmental morbidity at 1 year of age following extremely preterm delivery over a 20-year period: a single centre cohort study. Acta Paediatr. 2008;97:159-65.

4. Howlader N, Noone AM, Krapcho M, Garshell J, Miller D, Altekruse SF, Kosary CL, Yu M, Ruhl J, Tatalovich Z, Mariotto A, Lewis DR, Chen HS, Feuer EJ, Cronin KA (eds). SEER Cancer Statistics Review, 1975-2012. Bethesda: National Cancer Institute. http://seer.cancer.gov/csr/1975_2012/, based on November 2014 SEER data submission, posted to the SEER web site. April 2015

5. Lotstein DS, Inkelas M, Hays RD, Halfon N, Brook R. Access to care for youth with special health care needs in the transition to adulthood. J Adolesc Health. 2008:43:23-9.

6. McDonagh JE. Growing up and moving on: transition from pediatric to adult care. Pediatric Transplanatation. 2005;9:364-72.

7. Reiss J, Gibson R. Health care transition: destinations unknown. Pediatrics. 2002;110(Supplement 3):1307-14.

8. Wojciechowski EA, Hurtig A, Dorn L. A natural history study of adolescents and young adults with sickle cell disease as they transfer to adult care: a need for case management services. J Pediatr Nurs. 2002;17:18-27.

9. Betz CL. Transition of adolescents with special health care needs: review and analysis of the literature. Issues Comprehensive Pediatric Nursing. 2004;27:179-241.

10. Ginsberg JP, Hobbie WL, Carlson CA, Meadows AT. Delivering long-term follow-up care to pediatric cancer survivors: transitional care issues. Pediatr Blood Cancer. 2006:46:169-73.

11. Maughan BCL. Risk and protective factors in transitioning to young adulthood. In: Baltes PB, Baltes MM, editors. Successful aging: perspectives from the behavioral science. New York: Cambridge University; 1990. p. 296-331.

12. Kennedy A, Sawyer S. Transition from pediatric to adult services: are we getting it right? Curr Opin Pediatr. 2008;20:403-9.

13. Blum RW, Garell D, Hodgman CH. Transition from childcentered to adult health-care systems for adolescents with chronic conditions. A position paper of the Society for Adolescent Medicine. J Adolesc Health. 1993;14:570-6.

14. Blum RW, Hirsch D, Kastner TA, Quint RD, Sandle AD. A consensus statement on health care transition for young adults with special health care needs. Pediatrics. 2002;110(Supplement 3):1304-6.

15. Bronheim S, Fiel S, Schidlow D, MaGrab P, Boczar K, Dillon C. Crossing: A manual for transition of chronically III youth to adult health care. Washington, DC: Georgetown University Child Development Center; 1990. 
16. Royal College of Nursing. Adolescent transitional care guidance for nursing staff. 2013. Available at https://www2.rcn.org.uk/_data/assets/pdf_file/0011/ 78617/004510.pdf.

17. van Staa A, Jedeloo S, van Meeteren J, Latour JM. Crossing the transition chasm: experiences and recommendations for improving transitional care of young adults, parents and providers. Child Care Health Dev. 2011;37:821-32.

18. Gaston C, Rice M. Audit of the greater metropolitan services implementation and transition process: a report to NSW health. Sydney: NSW Health; 2003.

19. McDonagh JE, Kelly DA. Transitioning care of the pediatric recipient to adult caregivers. Pediatr Clin N Am. 2003;50:1561-83.

20. Betz CL, Nehring WM, Lobo ML. Transition needs of parents of adolescents and emerging adults with special health care needs and disabilities. J Fam Nurs. 2015;21:362-412.

21. Betz CL, Smith KA, Macias K, Deavenport-Saman A. Testing the transition preparation training program: well-being of relationships outcomes. J Pediatr Rehabil Med. 2015:8:235-46.

22. Betz CL, Ferris ME, Woodward JF, Okumura MJ, Jan S, Wood DL. The health care transition research consortium health care transition model: A framework for research and practice. J Pediatr Rehabil Med. 2014;7:3-15.

23. Fair C, Cuttance J, Sharma N, Maslow G, Wiener L, Betz C, Porter J, McLaughlin S, Gilleland-Marchak J, Renwick A, Naranjo D, Jan S, Javalkar K, Ferris $\mathrm{M}$. International and interdisciplinary identification of health care transition outcomes. JAMA Pediatr. 2016;170:205-11.

24. Rosen DS, Blum RW, Britto M, Sawyer SM, Siegel DM. Transition to adult health care for adolescents and young adults with chronic conditions: position paper of the Society for Adolescent Medicine. J Adolesc Health. 2003:33:309-11.

25. Hepburn CM, Cohen E, Bhawra J, Weiser N, Hayeems RZ, Guttmann A. Health system strategies supporting transition to adult care. Arch Dis Child. 2015;100:559-64.

26. Collis F, Finger E, Okerstrom E, Owens K. Review of transition of young adults clinics. Final report - Attachment 6: Literature review; 2008. Retrieved from http://www.aci.health.nsw.gov.au/_data/assets/pdf_file/0007/155779/ literaturereview.pdf.

27. Garvey KC, Markowitz JT, Laffel LM. Transition to adult care for youth with type 1 diabetes. Curr Diab Rep. 2012;12:533-41.

28. Beskine $D$, Owen $P$. Review of transitional care for young people with diabetes. Journal of Diabetes Nursing. 2008;12:34-8.

29. Daneman D, Nakhla M. Moving on: transition of teens with type 1 diabetes to adult care. Diabetes Spectrum. 2011;24:14-8.

30. Davies MC. Lost in transition: the needs of adolescents with Turner syndrome. BJOG. 2010;117:134-6.

31. American Academy of Pediatrics, American Academy of Family Physicians, American College of Physicians, Transitions Clinical Report Authoring Group. Supporting the health care transition from adolescence to adulthood in the medical home. Pediatrics. 2011;128:182-202.

32. Reiss JG, Gibson RW, Walker LR. Health care transition: youth, family, and provider perspectives. Pediatrics. 2005;115:112-20.

33. Clarizia NA, Chahal N, Manlhiot C, Kilburn J, Redington AN, McCrindle BW. Transition to adult health care for adolescents and young adults with congenital heart disease: Perspectives of the patient, parent and health care provider. Can J Cardiol. 2009:25:317-22

34. Megan AM. Transition of care from pediatric to adult clinics. JAMA Pediatr 2013;167:684.

35. Bollegala N, Nguyen GC. Transitioning the Adolescent with IBD from Pediatric to Adult Care: A Review of the Literature. Gastroenterol Res Pract. 2015;2015:853530.

36. Lam PY, Fitzgerald BB, Sawyer SM. Young adults in children's hospitals: why are they there? Med J Aust. 2005;182:381-4.

37. McPheeters M, Davis AM, Taylor JL, Brown RF, Potter SA, Epstein Jr RA Transition care for children with special health needs; 2014. Retrieved from https://www.effectivehealthcare.ahrq.gov/ehc/products/546/1920/childrenspecial-needs-transition-report-140617.pdf

38. Kadan-Lottick NS, Robison LL, Gurney JG, Neglia JP, Yasui Y, Hayashi R, Mertens AC. Childhood cancer survivors' knowledge about their past diagnosis and treatment: Childhood Cancer Survivor Study. Jama. 2002;287:1832-9.

39. Park ER, Li FP, Liu Y, Emmons KM, Ablin A, Robison LL, Mertens AC. Health insurance coverage in survivors of childhood cancer: the Childhood Cancer Survivor Study. J Clin Oncol. 2005:23:9187-97.
40. Henderson TO, Friedman DL, Meadows AT. Childhood cancer survivors: transition to adult-focused risk-based care. Pediatrics. 2010;126:129-36.

41. Wong HL, Chan WK, Wong YY, Wong LY, Huen KF, Yeoh EK, Fok TF. Transition care for adolescents and families with chronic illnesses. J Adolesc Health. 2010;47:540-6.

42. Ishizaki $Y$, Maru M, Higashino $H$, Katsumoto S, Egawa K, Yanagimoto $Y$, Nagahama T. The transition of adult patients with childhood onset chronic diseases from pediatric to adult healthcare systems: a survey of the perceptions of Japanese pediatricians and child health nurses. Bio Psycho Social Medicine. 2012;6:8

43. Ishizaki Y. Why is the transition planning necessary for carry over patients of childhood-onset chronic disease? J Theor Biol. 2011;93:1990-3.

\section{Submit your next manuscript to BioMed Central and we will help you at every step:}

- We accept pre-submission inquiries

- Our selector tool helps you to find the most relevant journal

- We provide round the clock customer support

- Convenient online submission

- Thorough peer review

- Inclusion in PubMed and all major indexing services

- Maximum visibility for your research

Submit your manuscript at www.biomedcentral.com/submit
) Biomed Central 